\title{
PROPOSTA DE PROCEDIMENTO METODOLÓGICO PARA IDENTIFICAÇÃO DE SUBCENTROS URBANOS
}

\author{
Moisés John dos Santos Alves Souza \\ Universidade Federal de Goiás (UFG) \\ Programa de Pós-graduação Projeto e Cidade, GO, Brasil \\ john.moises.sas@gmail.com \\ Erika Cristine Kneib \\ Universidade Federal de Goiás (UFG) \\ Programa de Pós-graduação Projeto e Cidade, GO, Brasil \\ erikakneib@ufg.br
}

\begin{abstract}
RESUMO
O presente trabalho apresenta como objetivo geral o desenvolvimento de um procedimento metodológico que permita a identificação de subcentros a partir da variável comércio e serviços. A justificativa se relaciona à necessidade de desenvolvimento de uma metodologia que possibilite localizar, caracterizar e identificar subcentros de comércio e serviços, buscando uma contribuição teórica e aplicada sobre o estudo das centralidades urbanas. O procedimento busca identificar subcentros a partir de valores de corte, em escala de bairro, utilizando as variáveis total de empresas de comércio e serviços e densidade de empresas de comércio e serviços. A cidade de Anápolis, no estado de Goiás, é o estudo de caso para teste e validação do procedimento metodológico proposto. Como resultados, foram identificados dois subcentros na referida cidade. À luz do referencial teórico abordado, a análise dos subcentros identificados permitiu localizar o centro expandido da cidade e um subcentro popular.
\end{abstract}

Palavras-chave: Procedimento metodológico. Centralidade Urbana. Subcentros. Comércio e serviços.

\section{METHODOLOGICAL PROCEDURE PROPOSAL FOR URBAN SUBCENTERS IDENTIFICATION}

\begin{abstract}
This work presents as a general objective the development of a methodological procedure that allows the identification of sub centers based on the variable trade and services. The justification is related to the need to develop a methodology that makes it possible to locate, characterize and identify sub-centers of trade and services, seeking a theoretical and applied contribution on the study of urban centralities. The procedure seeks to identify sub centers based on cut-off values, on a district scale, using the variables total of trade and services companies and density of trade and services companies. The city of Anápolis, in the state of Goiás, is the case study for testing and validating the proposed methodological procedure. As a result, two sub-centers were identified in that city. In the light of the theoretical framework addressed, the analysis of the identified sub centers made it possible to locate the expanded center of the city and a popular sub center.

Keywords: Methodological procedure. Urban centrality. Subcenters. Trade and services.
\end{abstract}

\section{INTRODUÇÃO}

A nova dinâmica de mobilidade urbana, propiciada pelo surgimento do automóvel, gerou significativas mudanças na configuração espacial das cidades brasileiras. Com as novas possibilidades de mobilidade urbana, foi possível expandir as direções de crescimento (VILLAÇA, 2001).

Devido à expansão urbana das grandes cidades, a existência de um único centro não mais foi suficiente para atender a cidade como um todo. Iniciou-se, assim, um processo de formação de novas centralidades mais próximas às novas áreas residenciais. Novas centralidades surgiram para diferentes classes e em diferentes regiões do espaço urbano (SILVA, 2001). Este processo iniciou-se com o abandono do centro tradicional pelas camadas de alta renda. Com as novas possibilidades de deslocamento no espaço urbano, as classes de alta renda puderam expandir suas direções de crescimento residencial para além do centro tradicional. Para compensar a perda de acessibilidade ao centro, essas classes logo fizeram surgir um novo centro, o denominado centro expandido. Por outro lado, para as classes menos abastadas, restou o centro tradicional abandonado pelas classes de alta

Caminhos de Geografia

Uberlândia-MG

v. 23, n. 85

fev./2022

p. 293-314

Página 293 
renda. Contudo, as dificuldades de acesso a este centro logo fizeram surgir centralidades mais acessíveis nas periferias (VILLAÇA, 2001).

A partir da diversidade urbana e dos processos urbanos, observa-se que há diferentes tipos de centralidades. Para uma análise mais acurada, se faz necessária a identificação das centralidades urbanas. A identificação e análise de centralidades tornou-se prática nos estudos urbanos, na medida em que surgiram novas centralidades decorrentes do processo de descentralização e (re)centralização das atividades terciárias, a exemplo dos estudos de Sposito (2013); Maia; Whitacker; Silva (2017); Villaça (2001) e Corrêa (1989).

Para além da análise teórica do processo de formação de centralidades, é importante localizá-las, caracterizá-las e dimensioná-las. Assim, é possível identificar os diferentes tipos de centralidades, tais como: centro expandido; subcentros; eixos comerciais; e centros comerciais (shoppings centers e similares). As centralidades não são homogêneas, há expressões de centralidades voltadas para diferentes classes e em diferentes regiões do espaço urbano. Portanto, é fundamental que se identifiquem as diferentes expressões de centralidades urbanas. Neste trabalho, o foco recai sobre os subcentros de comércio e serviço, devido a uma melhor possibilidade de leitura do processo de descentralização e (re)centralização das atividades terciárias.

Mesmo sendo prática nos estudos urbanos, as metodologias existentes para identificação de subcentros, são, em sua maioria, voltadas para identificação de subcentros de emprego (KNEIB, 2008). Assim sendo, para a análise do processo de formação de centralidades de comércio e serviços é preciso que se identifiquem centralidades a partir da variável comércio e serviços.

A partir destas considerações, a pesquisa busca responder a seguinte questão: Como definir e identificar subcentros urbanos de comércio e serviços no contexto das cidades brasileiras?

Sendo assim, o presente trabalho apresenta como objetivo geral o desenvolvimento de um procedimento metodológico que permita a identificação de subcentros a partir da variável comércio e serviços. Como objetivo específico, o trabalho busca abordar a respeito do processo redefinição de centralidades urbanas.

O procedimento, aqui apresentado, busca identificar subcentros a partir de valores de corte. Destarte, os bairros são analisados a partir do total de empresas de comércio e serviços e densidade de empresas de comércio e serviços. Como referência principal, tem-se o estudo de Giuliano e Small (1991). O procedimento dos autores é o mais difundido dentre os procedimentos para identificação de subcentros de emprego. Contudo, no estudo que ora se propõe, busca -se identificar subcentros a partir da variável comércio e serviços. Os subcentros são o objeto de pesquisa e se configuram, neste trabalho, como uma réplica em menor escala do Centro principal, caracterizando-se por sua elevada concentração de estabelecimentos de comércio e prestação de serviços.

O procedimento possibilita obter resultados quantitativos no que se refere à localização, importância e extensão dos subcentros de comércio e serviços a serem identificados e analisados nos estudos da Geografia Urbana e mesmo de outras ciências, como Urbanismo e Economia Urbana. Os estudos de análise e identificação de centralidades são recorrentes na Geografia, contudo, carecem de metodologias quantitativas para identificação e localização de subcentros de comércio e serviços.

Desta forma, a justificativa geral do trabalho se relaciona à necessidade de desenvolvimento de uma metodologia que possibilite localizar, caracterizar e identificar subcentros de comércio e serviços, buscando uma contribuição teórica e aplicada relativa ao estudo das centralidades urbanas de comércio e serviços.

A cidade de Anápolis é o estudo de caso para teste e validação do procedimento metodológico proposto. A escolha da referida cidade se dá pelo seu papel de destaque na rede urbana regional, sendo classificada pelo IBGE como centro sub-regional nível A (Regiões de Influência das Cidades 2007. IBGE, 2008), além de possuir um desenvolvido setor terciário que atrai consumidores provenientes de 34 municípios abrangendo Goiás e o sul do estado de Tocantins (SPOSITO; SPÓSITO, 2006).

Como resultados, foram identificados três subcentros na cidade Anápolis, Goiás. A aplicação do estudo de caso permitiu a validação do procedimento metodológico proposto. E ainda, à luz do referencial, a análise dos subcentros identificados permitiu localizar o centro Expandido e outros dois subcentros.

\section{O PROCESSO DE REDEFINIÇÃO DE CENTRALIDADES}

Embora o objetivo central deste trabalho seja de cunho estritamente metodológico, se faz necessário, considerando que o trabalho tem os subcentros urbanos como objeto de estudo, abordar o processo

$\begin{array}{lllll}\text { Caminhos de Geografia } & \text { Uberlândia-MG } & \text { v. 23, n. } 85 & \text { fev./2022 } & \text { p. 293-314 Página } 294\end{array}$


de redefinição de centralidades. Destarte, a análise dos subcentros identificados com o procedimento metodológico proposto será feita com base no referencial teórico aqui abordado. O entendimento sobre o processo de redefinição de centralidades aqui apresentado alinha-se à abordagem de Villaça (2001), sendo este autor basilar para este trabalho. Villaça (2001) faz uma análise histórica do processo, destacando a atuação das classes de alta renda como agentes hegemônicos. Na discussão, o autor busca evidenciar o papel da acessibilidade na formação de centralidades de comércio e serviços.

Em linhas gerais, o processo de redefinição de centralidades se configura enquanto processo de descentralização conjugado ao de (re)centralização das atividades terciárias (SPOSITO 1998; 2001), no qual o domínio e preeminência de um único centro dá lugar a uma estrutura composta por uma cadeia de centralidades dispersas e segregadas.

Apesar do surgimento de novas centralidades, o centro tradicional segue exercendo hegemonia frente a outros espaços de consumo, pois nele concentram-se os principais estabelecimentos comerciais e equipamentos urbanos (CORRÊA, 1989). Para Balsas (1999), o centro tem seu status-quo meramente ligado a esta multifuncionalidade orgânica, de tal modo que em sentido lato, o mesmo não permaneceria como centro sem esta característica: "[...] um centro de cidade é mais que um centro comercial. No entanto, se perder a sua atratividade como centro de comércio, dificilmente pode sobreviver como um centro em sentido lato" (BALSAS, 1999, p. 53). O centro perde sua conotação monopolista na medida em que se proliferam novos subcentros, passando então a denominar-se como "centro principal" (MAIA; WHITACKER, SILVA, 2017).

Os subcentros são réplicas em menor escala do centro principal, são áreas do espaço urbano que se caracterizam por sua elevada concentração de estabelecimentos de comércio e prestação de serviços, sendo que muitos de seus estabelecimentos são filiais, tendo suas sedes localizadas no centro tradicional (CORRÊA, 1989).

A principal diferença entre centro e subcentros está na escala de abrangência. Os subcentros buscam atender às demandas locais. Por outro lado, o centro o faz para a cidade como um todo (PANERAI, 2014; SILVA, 2001; VILLAÇA, 2001; CORRÊA, 1989). Segundo os autores, a escala de abrangência do centro principal vai além de seu espaço intraurbano. Ele constitui-se como foco principal também de sua hinterlândia.

É neste sentido que, do ponto de vista do consumidor, a formação de subcentros urbanos significa maior acessibilidade aos espaços de consumo. A dita acessibilidade é entendida aqui como a facilidade de acesso a bens, serviços e atividades (VASCONCELLOS, 2001; 2002; LITMAN, 2008), é um atributo que traduz a possibilidade de cada indivíduo citadino alcançar e participar de atividades de seu interesse (DE SOUZA NETO et. al., 2013). Assim, a existência de subcentros, quer para as classes de alta renda, quer para as classes de baixa renda, possibilita atender aos requisitos de otimização de acesso aos espaços de consumo: "[...] os centros principais e os subcentros [se formam] atendendo aos interesses dos deslocamentos de pessoas, organizadas em classes" (VILLAÇA, 2001, p. 354).

Do ponto de vista do mercado, a formação de centralidades significa expansão do capital comercial. O crescimento demográfico e espacial das cidades amplia o mercado consumidor e a competição por este mercado induz empresas da área central, ou mesmo novas empresas, a abrirem filiais em bairros (CORRÊA 1989). No entanto, a descentralização do capital comercial só ocorre se houver áreas plenamente propícias para o segmento comercial, isto é, áreas com acessibilidade e com um mercado consumidor que justifique essa localização (CORRÊA, 1989).

Após a ruptura com a estrutura urbana caracterizada pela existência de um único centro, a lógica de localização do setor terciário está na busca por áreas com desenvolvida acessibilidade. A acessibilidade foi um elemento importante inclusive na formação do próprio centro tradicional. Segundo Villaça (2001), o centro o é por sua acessibilidade, de maneira que, sem esse atributo, dificilmente o mesmo atrairia para si empreendimentos comerciais.

A circulação gerada pela acessibilidade é tida para o segmento comercial como um mercado consumidor em potencial. Assim, áreas com intensa circulação de veículos e pessoas, tais como as inseridas em importantes vias de acesso e próximas aos Polos Geradores de Viagens - PGV (nesse caso, no que diz respeito aos transportes), se constituem como áreas estratégicas para concentração de estabelecimentos comerciais: "[...] ruas ou avenidas que, por constituírem importantes vias de acesso aos principais bairros, a circulação nelas concentrada provoca intenso movimento diário de pessoas que se deslocam de um ponto a outro da cidade, atraindo para si lojas comerciais importantes" (DUARTE, 1974, p. 86).

$\begin{array}{llllll}\text { Caminhos de Geografia } & \text { Uberlândia-MG } & \text { v. 23, n. } 85 & \text { fev./2022 } & \text { p. 293-314 } & \text { Página } 295\end{array}$


A acessibilidade se apresenta, assim, como o valor de uso mais importante para a terra urbana (VILLAÇA, 2001). O valor de uso do espaço é diferente do valor dos elementos que o constituem. Segundo Villaça (2001), é equivocado achar que são apenas as estruturas que dão valor de uso à terra urbana. Há, neste caso, dois valores a se considerar: o valor das estruturas em si; e o valor produzido pela aglomeração, fruto do trabalho social. Este último é dado pela localização mais ou menos privilegiada do terreno ou edifício. Sendo que a acessibilidade se constitui no principal valor de uso (PEREIRA, 2001; VILLAÇA, 2001).

Todos os terrenos urbanos têm algum grau de acessibilidade, o que se diz é que quanto maior a acessibilidade da terra urbana, maior seu valor de uso, logo, maior seu valor monetário. Diferentes pontos do espaço urbano têm diferentes graus de acessibilidade. Essa qualidade demonstra a quantidade de trabalho socialmente necessário despendido em sua produção. Nesse sentido, terrenos mais centrais têm mais trabalho dispendido em sua produção, os terrenos periféricos o têm menos (VILLAÇA, 2001). No caso das centralidades, paga-se pelo "ponto" comercial. A expressão popular "passa-se esse ponto", quando um proprietário anuncia a venda de um edifício ou terreno potencial para o comércio, reflete bem como o preço da localização se sobrepõe ao preço das estruturas. Assim, paga-se não pela edificação, mas sim, pela localização privilegiada (VILLAÇA, 2001).

O aumento do valor de uso, decorre, sobretudo, da melhoria da acessibilidade. Por exemplo, dois terrenos voltados para instalação de estabelecimentos comerciais em pontos distintos do espaço urbano, mesmo com estruturas físicas similares, podem ter valores diferentes. Considerando a sobreposição do valor de localização, o lote de maior valor monetário seria aquele localizado na região com maior acessibilidade, pois a acessibilidade propicia maior circulação de veículos e pessoas.

No entanto, no caso das cidades brasileiras, essa qualidade urbana é ofertada de modo desigual. Devido à atuação segregada do Estado, a direção de crescimento residencial das classes de alta renda acaba por obter as melhores condições de acessibilidade (VILLAÇA, 2001). Essa atuação segregacionista do poder público se tornou mais evidente e necessária, do ponto de vista das classes de alta renda, quando estas abandonaram o centro tradicional como espaço de moradia. Após o abandono do centro tradicional, o poder público procurou investir em suas novas áreas residenciais, a fim de compensar a perda da acessibilidade ao centro por elas abandonado.

Antes do surgimento do automóvel, o centro tradicional foi, por muitas décadas, a área residencial das classes de alta renda. A sua permanência no centro esteve ligada à acessibilidade que detinham aos espaços de consumo. Com as novas condições de deslocamento, propiciadas pelo uso do automóvel, essas classes puderam firmar novas direções de crescimento residencial (ÁLVAREZ, 2015). Assim, o automóvel foi visto como um meio para se manter acesso ao centro tradicional mesmo residindo em localidades distantes (ÁLVAREZ, 2015; SILVA, 2004; VILLAÇA, 2001).

Como destacado, além da proliferação do automóvel, a atuação segregacionista do poder público na promoção de infraestruturas viárias contribuiu para a melhoria da acessibilidade na direção de crescimento residencial das classes de alta renda, possibilitando amenizar a perda da acessibilidade ao centro por elas abandonado. Mas, para que este esquema fosse bem-sucedido, foi necessário que essas classes firmassem uma única direção de crescimento residencial. A partir deste modelo de estruturação, observa-se que os bairros das camadas de alta renda tendem a crescer formando setores de círculo (VILLAÇA, 2001).

O modelo de setores de círculo se baseia na constatação de que a estruturação das cidades brasileiras tende a se concretizar segundo setores. O modelo é trabalhado por Villaça (2001) em 'Espaço intraurbano no Brasil'. O autor faz referência ao modelo de setores de Hoyt, o aplicando ao contexto das cidades brasileiras. A abordagem possibilita uma leitura mais aguçada do processo de redefinição de centralidades, permitindo compreender seus aspectos de maneira ampla. Há outros modelos bastante difundidos, como é o caso do modelo de círculos concêntricos proposto por Burgess (SILVA, 2004). Contudo, esse modelo foi elaborado para o contexto das cidades americanas (Estados Unidos da América). Já o modelo trabalhado por Villaça (2001) considera especificamente o contexto das cidades brasileiras.

A essência da organização espacial radial e em setores está na necessidade de maior controle operacional das classes de alta renda sobre o espaço urbano, e, no caso específico das centralidades, "[está na] necessidade de manter acesso ao centro da cidade" (VILLAÇA, 2001, p. 153). Em outras palavras, a concentração em setores permite que a administração pública, por elas dominada, tenha uma direção melhor definida para aplicação segregada de recursos - no que diz respeito à mobilidade e à acessibilidade: "Essa classe, e o Estado por ela dominado, produziram então um espaço urbano

$\begin{array}{lllll}\text { Caminhos de Geografia } & \text { Uberlândia-MG } & \text { v. 23, n. } 85 & \text { fev./2022 } & \text { p. 293-314 Página } 296\end{array}$


em que elas podiam desfrutar ao máximo as opções que a liberdade espacial lhes oferecia" (VILLAÇA, 2001, p. 280).

Inicialmente foi essa acessibilidade o principal fator que propiciou a formação do centro expandido. Contudo, como é discutido no decorrer do tópico, a descentralização comercial se intensificou também pela desmotivação comercial do centro para o comércio sofisticado e, ainda, pela falta se espaço para expansão comercial e pela especulação imobiliária.

Os desenvolvidos padrões em acessibilidade, na direção de crescimento residencial das classes de alta renda, atraíram o setor terciário, propiciando a formação de um novo centro, o centro expandido. A estruturação em setores, associada ao sistema viário existente nas cidades brasileiras, mostram o relevante papel da acessibilidade na atração do comércio e dos serviços (VILLAÇA, 2001).

Para além da atuação junto ao Estado na busca por investimentos em mobilidade urbana na sua direção de crescimento residencial, a criação de um novo centro foi mais uma das manobras encontradas pelas classes de alta renda na busca por minimizar a perda da acessibilidade aos espaços de consumo. As classes de alta renda se depararam com esse problema após o abandono do centro tradicional, outrora seu espaço de moradia e consumo. Num primeiro momento, o centro tradicional é abandonado apenas como espaço de moradia, mas com a formação do centro expandido, é abandonado também como espaço de consumo.

O centro expandido é um novo centro caracterizado pela concentração de empreendimentos voltados para o consumo de luxo. O centro expandido é resultado da busca por acessibilidade aos espaços de consumo por parte das classes de alta renda. Na medida em que se afastaram do centro tradicional, as classes de alta renda procuraram minimizar a perda de acessibilidade ao mesmo, expandindo-o para sua direção de crescimento:

Foram os interesses de locomoção dessa classe que modelaram, a partir da década de 1970, uma parte dos territórios, "[...] inclusive seus centros. A mobilidade territorial [...] para as famílias que conseguiram aumentá-la, ampliou-se o raio de ação dentro do qual podiam fazer uso do comércio e dos serviços. Aumentaram seu raio de ação em função da clientela motorizada" (VILLAÇA, 2001, p. 280).

Com a deterioração do centro tradicional, a lógica de expansão do setor terciário está no crescimento geograficamente direcionado aos novos bairros elitizados (pelos desenvolvidos padrões em acessibilidade que se encontram nas direções dos setores das classes de alta renda), daí a formação do centro expandido: "a década de 1960 marcou, em todas as nossas metrópoles e mesmo em cidades médias, o início do desenvolvimento de grandes "sub-regiões urbanas" de comércio e serviços voltados para as camadas de alta renda [...] que se localizavam no centro principal" (VILLAÇA, 2001, p. 277).

Com o surgimento do centro expandido, os centros tradicionais foram deixados a deteriorar, sendo, agora, abandonados não só como espaço de moradia, mas também como espaço de consumo. Relegados aos pobres, foram apropriados pelo comércio informal (CORRÊA, 1989; VILLAÇA, 2001). O termo "deteriorar-se" consiste nas causas e efeitos do processo de abandono/desocupação das edificações do centro e a consequente alteração dos fluxos. As classes populares ficaram então com o "centro velho" e com os subcentros periféricos (VILLAÇA, 2001).

Por um lado, houve uma nova lógica de crescimento das camadas de alta renda e, por outro, no caso das classes populares, Ihes restaram as periferias. A crescente urbanização fez surgir subúrbios voltados para as classes baixa e média baixa, cada vez mais distantes do centro tradicional. As permanentes dificuldades de acesso ao centro tradicional contribuíram para a proliferação de áreas de consumo mais acessíveis às periferias - os subcentros (VILLAÇA, 2001).

As condições de deslocamento no espaço intraurbano variam conforme as classes sociais. Prisioneira do espaço, a população de baixa renda, que é maioria nas cidades brasileiras, possui as piores condições de deslocamento (VASCONCELLOS, 2001). O transporte, a mobilidade e a acessibilidade no espaço urbano são socialmente produzidos e refletem as contradições sociais (LESSA, 2019). Os fatores que dificultam o deslocamento destas classes estão ligados, principalmente, à baixa qualidade do serviço de transporte público (VASCONCELLOS, 2002), o que contribui consideravelmente para o aumento do tempo gasto em deslocamentos até o centro principal ou mesmo a outras regiões do espaço urbano.

Tal como na formação do centro expandido, inicialmente, a proliferação de subcentros revelou a busca pela otimização de acesso aos espaços de consumo. Diferentemente das classes de alta renda, a

$\begin{array}{lllll}\text { Caminhos de Geografia } & \text { Uberlândia-MG } & \text { v. 23, n. } 85 & \text { fev./2022 } & \text { p. 293-314 Página } 297\end{array}$


população de renda baixa ou média baixa não possui igual poder de atuação junto ao poder público na promoção de melhorias em acessibilidade aos espaços de consumo. Sendo assim, as necessidades básicas locais fizeram surgir novas centralidades mais acessíveis às periferias (PEREIRA, 2001; VILLAÇA, 2001). Contudo, segundo Villaça (2001), o mercado logo fez surgir subcentros voltados para todo tipo de classes, apesar do centro expandido ser essencialmente o espaço de consumo das classes de alta renda.

Neste processo de descentralização e (re)centralização das atividades terciárias, destaca-se ainda o surgimento dos shoppings centers. O primeiro empreendimento dessa natureza no Brasil foi inaugurado em 1966 na cidade de São Paulo (SP). Trata-se do Iguatemi Shopping Center. O segundo foi construído em 1968 na mesma cidade, sendo denominado como Shopping Center Lapa (DEVAI, 2014). A expansão dos shoppings centers em outras cidades brasileiras só ocorreu por volta da década de 1970.

Os shoppings centers se configuram por sua concentração de estabelecimentos voltados para classes de maior poder aquisitivo, são centros de compras que se assemelham aos equipamentos que outrora formavam o centro tradicional mononuclear (SILVA, 2001). Os shoppings centers não são confundidos com subcentros, contudo, representam novas formas de atuação do mercado nas relações de consumo. Apesar de sua proliferação, os shoppings centers ainda não diminuíram a hegemonia dos subcentros de forma significativa. Em realidade, há uma tendência para implantação de shoppings centers em subcentros já consolidados, fortalecendo a centralidade existente (VILLAÇA, 2001).

Esses empreendimentos envolvem forte atuação de agentes de produção do espaço urbano, em prol de interesses imobiliários e comerciais (CORRÊA, 1989). Os shoppings centers representam um processo de coesão e formação de áreas especializadas. Sua ampla rede de lojas e inovações tecnológicas formam um conjunto funcional e monopolista que atrai um grande mercado consumidor. Essas características tornam o shopping center um investimento atrativo para a iniciativa privada (DEVAI, 2014). Na perspectiva capitalista, os shoppings centers revelam, de um lado, a busca pela crescente especulação imobiliária, e de outro, a busca pela expansão do mercado consumidor.

A proliferação de shoppings centers representa um processo de mercantilização do espaço urbano através da produção de "pontos". A expressão "ponto" refere-se à transformação do espaço em mercadoria. Os "pontos" são determinadas localizações geográficas do espaço urbano consolidadas como potenciais para o comércio. Neste sentido, as melhores localizações para os shoppings centers são aquelas em que a há um desenvolvido mercado consumidor (VILLAÇA, 2001). E, novamente, a acessibilidade é um fator essencial para o sucesso desses empreendimentos (CORRÊA, 1989). São empreendimentos que tendem a se localizar em áreas com intensa circulação de veículos e pessoas.

A partir das abordagens, observa-se que o surgimento de novas centralidades é resultado da busca por acessibilidade aos espaços de consumo. Contudo, essa qualidade urbana é disputada. $\mathrm{O}$ que, consequentemente, cria espaços de consumo que se diferenciam em termos de padrões socioeconômicos e tipo de atividades (PEREIRA, 2001). Nesse processo, as classes de alta renda, devido a seu poder de atuação junto ao Estado e ao mercado, acabam por obter as melhores condições em acessibilidade aos espaços de consumo.

\section{IDENTIFICAÇÃO DE SUBCENTROS URBANOS}

A sessão anterior abordou questões relativas ao principal objeto deste trabalho, os subcentros. Apresentou ainda suas definições e características, os fundamentos, agentes e processos que envolvem o processo de redefinição de centralidades. A sessão que se segue apresenta metodologias e modelos associados à definição e identificação de subcentros. Metodologias estas que foram desenvolvidas, por seus autores, com o intuito de possibilitar uma análise mais acurada da estrutura urbana policêntrica.

Primeiramente, esta sessão elenca as metodologias mais difundidas no contexto internacional e nacional. Apresenta-se ainda algumas das metodologias aplicadas em Anápolis, que é o estudo de caso deste trabalho. Posteriormente, como este trabalho vislumbra a proposição de um procedimento para a identificação de subcentros, são apresentadas as técnicas e elementos que conformam o procedimento metodológico proposto.

As etapas do procedimento metodológico para identificação de subcentros, que propõem critérios para o estabelecimento de valores de corte; para cálculos de densidade de comércio e serviços; e para

$\begin{array}{lllll}\text { Caminhos de Geografia } & \text { Uberlândia-MG } & \text { v. 23, n. } 85 & \text { fev./2022 } & \text { p. 293-314 Página } 298\end{array}$


classificação dos subcentros de comércio e serviços serão validadas com sua aplicação no estudo de caso deste trabalho.

\section{Metodologias para identificação de subcentros urbanos}

As metodologias voltadas para a identificação de subcentros se difundiram, sobretudo, a partir da década de 1980, superando então as classificações empíricas fornecidas por agências de Planejamento Urbano (GIULIANO; SMALL, 1991). Tal como aponta Kneib (2008), são três as classes/categorias/ tipos de metodologias mais difundidas quanto à identificação de subcentros urbanos, a saber: i) Metodologias baseadas em Valores de Corte; ii) Metodologias baseadas em Métodos Econométricos; e iii) Metodologias baseadas em Análise de Dados Estatísticos Espaciais.

\section{Metodologias baseadas em valores de corte}

A identificação de subcentros a partir de metodologias baseadas em Valores de Corte consiste em utilizar limites inferiores pré-estabelecidos para determinadas variáveis. Destarte, os subcentros são as unidades de análise com dados superiores a um determinado valor de corte. Contudo, McMillen (2001) ressalta que neste procedimento não há valores de corte padronizados, sendo necessário conhecimento prévio do território a ser analisado para estabelecimento de valores de corte adequados. A variável empregos é a mais utilizada neste caso. Sendo assim, determina-se dois valores de corte, sendo um para densidade de emprego (número de empregos divididos pela área em análise) e outro para o total de empregos (KNEIB, 2008).

Dentre os estudos que identificam subcentros a partir de valores de corte, destaca-se no contexto internacional: Giuliano; Small (1991); Small; Song (1994); McDonald; McMillen (2000); e Baumont; Bourdon (2002). Entre os estudos aplicados em cidades brasileiras, destacam-se: Siqueira (2012) e o de Rodrigues; Belmiro; Silveira Neto (2018). O procedimento proposto neste trabalho baseia-se na metodologia Giuliano; Small (1991).

Giuliano; Small (1991) identificam subcentros na região da cidade de Los Angeles, estado da Califórnia, Estados Unidos da América. O método proposto pelos autores é o mais difundido dentre os métodos baseados em valores de corte (SIQUEIRA, 2012). Na metodologia proposta e aplicada por Giuliano; Small (1991), os subcentros são um conjunto de zonas contiguas, cada uma com densidade superior a $D$ (valor de corte), que juntas tenham pelo menos $E$ empregos totais (valor de corte). Em linhas gerais, neste procedimento, um subcentro é definido como um aglomerado de zonas contíguas para as quais o emprego total e a densidade de empregos excedem um limite predeterminado.

No estudo de Giuliano; Small (1991), os valores de corte ficaram em 10 empregos por acre para a densidade e 10.000 empregos totais por unidade de análise. Com a aplicação da metodologia, foram identificados 32 subcentros na região de Los Angeles. O método proposto e aplicado por Giuliano; Small (1991) utiliza dois parâmetros para identificação de subcentros, sendo um para densidade de empregos e outro para o total de empregos. A utilização de dois parâmetros possibilitou superar algumas lacunas presentes em outros métodos baseados em valores de corte, como é o caso do método proposto por McDonald (1987).

No estudo de McDonald (1987), os subcentros são zonas cuja concentração do emprego é maior do que todas as zonas adjacentes. Contudo, com este método, existe a possibilidade de se identificar subcentros com baixa densidade de emprego. Isto poderia ocorrer caso as zonas adjacentes obtivessem pouco ou nenhum emprego. Deste modo, o método proposto por Giuliano; Small (1991), utilizando dois parâmetros, em vez de apenas um, possibilita identificar subcentros com maior rigor estatístico. A utilização de dois parâmetros permite identificar subcentros considerando não apenas densidade, mas também quantidade. Desta forma, considera-se que um subcentro deve apresentar densidade e quantidade significativa de empregos, de modo que se sobressaia frente a todo o território em análise e não apenas às áreas circundantes.

Tal como Giuliano; Small (1991), Small; Song (1994) examinaram os padrões espaciais durante a década de 1970 na região da cidade de Los Angeles, estado da Califórnia, Estados Unidos da América, estimando funções de densidade monocêntrica e policêntrica para emprego e população. Small; Song (1994) concluíram que os modelos policêntricos se encaixaram estatisticamente melhor que os modelos monocêntricos para o caso de Los Angeles, e houve alguma mudança na distribuição de empregos em direção a um padrão mais policêntrico entre 1970 e 1980. Os valores de corte ficaram em 20 empregos

$\begin{array}{llllll}\text { Caminhos de Geografia } & \text { Uberlândia-MG } & \text { v. 23, n. } 85 & \text { fev./2022 } & \text { p. 293-314 Página } 299\end{array}$


por acre para a densidade e 20.000 para o total de empregos. Desta forma, foram identificados 7 subcentros no ano de 1970 e 10 no ano de 1980.

McDonald; McMillen (2000) identificaram subcentros na região metropolitana da cidade de Chicago, estado de llinóis, Estados Unidos da América, em 1980 e 1990. Os valores de corte para o estudo de McDonald; McMillen (2000) ficaram em 10 empregos por acre para a densidade e 10.000 para o total de empregos. $\mathrm{O}$ estudo identificou 20 subcentros em Chicago. Além disto, o estudo considerou, nas equações, a distância dos subcentros ao centro como uma das variáveis para explicar a densidade de empregos. Para os autores, a proximidade do subcentro tem uma influência significativa sobre a densidade.

Baumont; Bourdon (2004) identificaram subcentros na região de Dijon, região administrativa de Borgonha-Franco-Condado (desde 2014), França, em 1990 e 1999. A região em estudo compõe 16 cidades, sendo denominada como COMADI. A escala espacial usada pelos autores foi Zoneamento Iris-2000 para as comunas de mais de 5000 habitantes. A amostra analisou 114 zonas. Os autores concluíram o método analisando os clusters, observando diversas variáveis. Os valores de corte ficaram em 1.600 empregos em 1990 e 1.400 empregos em 1999. O trabalho buscou comparar os resultados obtidos em 1999 com os resultados do estudo anterior, aplicado em 1990. O estuco identificou 6 subcentros no ano de 1990 e novamente 6 subcentros no ano de 1999. Os autores testaram alguns valores de corte distintos, o que também gerou resultados distintos. Isto é, ao aumentar o valor de corte, menos subcentros são identificados e o inverso ocorre ao diminuir o valor de corte.

No contexto nacional destaca-se os estudos de Siqueira (2012) e de Rodrigues; Belmiro; Silveira Neto (2018) que identificaram subcentros em duas grandes metrópoles brasileiras: São Paulo, estado de São Paulo; e Recife, estado de Pernambuco.

No estudo de Siqueira (2012), o objetivo foi a identificação de subcentros na cidade de São Paulo (SP). Para identificação de subcentros na Grande São Paulo, o autor utilizou dados de Origem-Destino. Os dados foram provenientes da base de dados da pesquisa censitária amostral domiciliar de 2007, que abarca todos os municípios da Região Metropolitana de São Paulo. Os dados continham informações referentes a 120 mil entrevistados de 30 mil domicílios de 460 zonas. O estudo identificou subcentros a partir de dois procedimentos metodológicos, a saber: Valores de Corte; e Estatística Local de Moran. O valor de corte utilizado para densidade de empregos ficou em 30 trabalhadores por acre, considerando que a média de São Paulo é de 15 trabalhadores por acre. Pela metodologia baseada em valores de corte, o estudo de Siqueira (2012) identificou 75 zonas censitárias qualificadas como subcentros na cidade de São Paulo. Pela Estatística Local de Moran o estudo identificou 32 zonas censitárias qualificadas como subcentros. E ainda, 22 zonas censitárias foram qualificadas por ambos os métodos.

No estudo de Rodrigues; Belmiro; Silveira Neto (2018), o objetivo centrou-se na identificação de subcentros de emprego a partir da metodologia baseada em valores de corte, com aplicação na cidade do Recife. Os valores de corte utilizados no estudo foram: 10.000 trabalhadores por área; e, para densidade, 2.500 empregos por km². Os mesmos valores utilizados por Giuliano; Small (1991). A base de dados utilizada pelo autor foram as informações contidas nos dados do Imposto sobre a Transmissão de Bens Imóveis (ITBI), fornecidas pela Relação Anual de Informações Sociais (RAIS) e pela Secretaria da Fazenda de Pernambuco. Após aplicação da metodologia, o estudo de Rodrigues; Belmiro; Silveira Neto (2018) concluiu que a cidade do Recife tem estrutura territorial monocêntrica.

Observa-se que a variável empregos é a mais utilizada na identificação de subcentros a partir de metodologias baseadas em valores de corte. Contudo, há estudos que utilizam diferentes variáveis. López; Muñiz (2006) destacam alguns estudos que utilizam variáveis e bases de dados distintas para identificação de subcentros, tais como: Martori; Suriñac (2002), que identificam subcentros considerando limiar de população; Asensio (2000), que identifica subcentros considerando taxas de emprego; e ATM (1998), que identifica subcentros considerando fluxos pendulares. Para o procedimento metodológico proposto neste trabalho, busca-se identificar subcentros pela variável comércio e serviços, conforme será abordado adiante.

\section{Metodologia baseada em Métodos econométricos}

Os métodos econométricos sugerem a identificação de subcentros a partir de resíduos positivos calculados a partir de uma função exponencial de densidade de empregos. Outro modo de identificação seria a partir de métodos não paramétricos (Siqueira, 2014), como proposto por McMillen (2001).

$\begin{array}{lllll}\text { Caminhos de Geografia } & \text { Uberlândia-MG } & \text { v. 23, n. } 85 & \text { fev./2022 } & \text { p. 293-314 Página } 300\end{array}$


O estudo de McMillen (2001) preconizou um procedimento baseado em duas etapas distintas: a primeira etapa consiste em definir uma variável não paramétrica estimativa para identificação de subcentros, sendo baseada na Locally Weighted Regression - LWR (Regressão Ponderada Localmente) em modelo estatístico gaussiano. A segunda etapa consiste na análise da significância da densidade de empregos das unidades de análise a partir de uma regressão semi-paramétrica. Neste sentido, as unidades que apresentam resíduos positivos são qualificadas como subcentros, sendo dispensável o conhecimento prévio do território analisado. McMillen (2001) aponta que os métodos econométricos possibilitam maior rigor e exatidão para a identificação de subcentros, mesmo que o pesquisador não conheça o território de forma minuciosa. Porém, o número de subcentros identificados varia de acordo com o recorte espacial empreendido pelo pesquisador.

\section{Metodologia baseada em dados estatísticos espaciais}

A análise exploratória de dados espaciais (AEDE) consiste no uso de dados estatísticos que possibilitem leituras espaciais geográficas. Assim como na metodologia baseada em métodos econométricos, a análise feita a partir de dados espaciais se caracteriza por seu rigor estatístico. Como coloca Kneib (2008), este método permite a identificação de autocorrelação espacial entre as unidades amostrais vizinhas na forma de clusters espaciais ou mesmo de heterogeneidade na forma de clusters diferenciados.

Destaca-se o estudo de Baumont; Bourdon (2004) que identifica subcentros na região de Dijon, França. Baumont; Bourdon (2004) analisam os padrões espaciais de emprego a partir da análise de dados espaciais geográficos. Os autores propõem um método alternativo usando a Análise Exploratória de Dados Espaciais - ESDA. Neste caso, os subcentros são identificados como áreas com densidade de empregos potencialmente mais alta que a de áreas circundantes. A ESDA é um aparato de técnicas objetivadas em descrever distribuições espaciais em termos de autocorrelação espacial global, autocorrelação espacial local e heterogeneidade espacial. Neste caso, a ESDA é aplicada nas distribuições de emprego total e na densidade de empregos (BAUMONT; BOURDON, 2004).

No caso nacional pode ser citado o trabalho de Kneib (2008), que desenvolve um procedimento para identificação de subcentros urbanos, a partir da ESDA, em escala de zonas de tráfego e setores censitários, utilizando análise da dependência espacial (diagrama de espalhamento de Moran e Boxmap), análise de áreas e superfícies. O procedimento é aplicado e validado para a cidade de Manaus, estado do Amazonas.

\section{Metodologias qualitativas aplicadas em Anápolis, Goiás}

Os estudos relativos à identificação de subcentros em Anápolis, cidade objeto deste estudo, utilizaram prioritariamente metodologias qualitativas. Mesmo não sendo metodologias difundidas internacional ou nacionalmente, a importância de apresentá-las sinteticamente se deve ao fato dos resultados da aplicação dos métodos qualitativos em Anápolis servirem como base para comparação com os resultados quantitativos obtidos no presente trabalho.

Dentre os estudos existentes em Anápolis, destaca-se os trabalhos de Luz (2013), Mendonça (2016) e Garcia (2012).

O estudo de Luz (2013) objetivou compreender o processo de descentralização das atividades terciárias no contexto das cidades médias. $O$ estudo analisou o surgimento de centralidades comerciais em Anápolis e identificou centralidades a partir de metodologia qualitativa. A partir de pesquisas de campo e análises de cunho teórico, o estudo identificou 2 subcentros e 1 eixo comercial, a saber: Subcentro Bairro Vila Jaiara, Subcentro Bairro Jundiaí e Eixo comercial Avenida Brasil Norte e Sul.

O estudo de Mendonça (2016) objetivou identificar e comparar as centralidades obtidas com a rede de transporte público coletivo, verificando algumas inconsistências existentes na rede. As centralidades foram identificadas a partir de metodologia qualitativa: a autora identificou centralidades a partir do Método Delphi adaptado à análise espacial, proposto por Kneib (2008). Posteriormente, as centralidades identificadas foram analisadas em conjunto com a rede de transportes, a partir de ferramentas dos Sistemas de Informação Geográfica - SIG. O estudo identificou 3 centralidades como semelhantes ao centro principal, a saber: Avenida Fernando Costa e áreas contiguas, no Bairro Vila Jaiara; Avenida São Francisco e áreas contiguas, no Bairro Jundiaí; e Avenida Tiradentes, localizada no Bairro Maracanã. O estudo identificou ainda outras centralidades com menor grau de importância segundo a metodologia aplicada.

$\begin{array}{lllll}\text { Caminhos de Geografia } & \text { Uberlândia-MG } & \text { v. 23, n. } 85 & \text { fev./2022 } & \text { p. 293-314 Página } 301\end{array}$


O estudo de Garcia (2012) objetivou compreender o processo de descentralização das atividades terciárias nas cidades médias e a formação de novos pontos de comércio, a partir da análise dos subcentros e eixos comerciais em Anápolis. A partir de pesquisas de campo e análises de cunho teórico, foram identificados 2 subcentros, a saber: Bairro Jundiaí e Bairro Vila Jaiara, além de 3 eixos comerciais: Avenida Brasil Norte e Sul, Avenida Universitária e Avenida Pedro Ludovico.

\section{PROPOSTA DE PROCEDIMENTO METODOLÓGICO PARA IDENTIFICAÇÃO DE SUBCENTROS}

Este trabalho se debruça sobre a proposição e teste de um procedimento metodológico que possibilite a identificação de subcentros de comércio e serviços utilizando valores de corte. Destarte, os subcentros são identificados pela quantidade de empresas de comércio e serviços. A utilização da variável comércio e serviços se dá pela possibilidade de análise aprofundada do processo de descentralização e (re)centralização das atividades terciárias.

Este procedimento metodológico tem como referência principal o estudo de Giuliano; Small (1991), que identifica subcentros a partir de valores de corte na cidade de Los Angeles. Optou-se pela metodologia baseada em valores de corte por sua viabilidade e possibilidade de identificação de subcentros tomando como base a referida variável. Para o caso da aplicação do procedimento em cidades brasileiras, os dados podem ser obtidos através do Cadastro Nacional da Pessoa Jurídica (acrônimo: CNPJ) junto à Receita Federal brasileira.

De modo geral, conforme as definições de Corrêa (1989), Villaça (2001) e Silva (2001), salientadas na primeira sessão deste trabalho, um subcentro se caracteriza por sua significativa concentração de empresas de comércio e prestação de serviços, de tal forma que se sobressai frente a outros bairros, e é comparável ao centro principal. Sendo assim, ao estabelecer os valores de corte, será levada em consideração a definição mencionada.

Em linhas gerais, as metodologias baseadas em valores de corte "identificam os subcentros a partir do estabelecimento de limites inferiores (valores de corte) para variáveis que possam atribuir às localidades do meio intraurbano características de lugares centrais" (SIQUEIRA, 2014, p.3). Portanto, para o estudo que ora se propõe, os subcentros são bairros com densidade de comércio e serviços acima de algum valor de corte $D$, e que tenha pelo menos $E$ empresas de comércio e prestação de serviços. No procedimento de Giuliano; Small (1991), utiliza-se a variável empregos, tanto para o valor de corte $D$, quanto para o valor de corte $E$. Já neste estudo, utiliza-se a variável empresas de comércio e serviços para os valores de corte $D$ e $E$.

O centro é definido como a zona de maior densidade e quantidade de empresas de comércio e prestação de serviços. Com esta definição, todas as zonas com valores acima de $D$ e $E$ são classificadas como subcentros em uma escala de bairro, de tal forma que:

$D=$ Valor de corte;

$E=$ Valor de corte;

Subcentros = Bairros com densidade de empresas de comércio e serviços maior que $D$ e com quantidade de empresas de comércio e prestação de serviços maior que $E$;

Não subcentros = Bairros com densidade de empresas de comércio e serviços menor que $D$ e/ou com quantidade de empresas de comércio e prestação de serviços menor que $E$.

\section{Do estabelecimento de valores de corte}

Conforme descrito no item "Metodologias baseadas em valores de corte", o estudo de Giuliano; Small (1991) se coloca como o estudo mais influente quanto à identificação de subcentros a partir de metodologias baseadas em valores de corte (SIQUEIRA, 2012). Giuliano; Small (1991) afirmam que os critérios para estabelecimento de valores de corte no estudo aplicado em Los Angeles foram governados pelo desejo de corresponder ao conceito teórico, sendo que os valores estabelecidos são, na visão dos autores: gerenciáveis, capazes de analisar o deslocamento para subcentros e adequados para análise estatística.

Contudo, os valores de corte utilizados por Giuliano; Small (1991) são considerados arbitrários por alguns pesquisadores que trabalham com a identificação de subcentros, dentre eles Baumont; Bourdon (2002). A metodologia baseada em valores de corte não estabelece critérios para definição dos valores de corte, cabe ao pesquisador encontrar um valor que se adeque à realidade da cidade em estudo.

$\begin{array}{lllll}\text { Caminhos de Geografia } & \text { Uberlândia-MG } & \text { v. 23, n. } 85 & \text { fev./2022 } & \text { p. 293-314 Página } 302\end{array}$


Buscando superar este entrave, o procedimento proposto neste trabalho tem como um dos objetivos desenvolver um procedimento metodológico que possibilite o estabelecimento de valores de corte. Com este procedimento, busca-se: i) estabelecer valores de corte ponderados. Isto é, nem ínfimos e nem exorbitantes; e ii) ser reaplicável. Ou seja, que possa ser aplicado em qualquer cidade brasileira, de forma que, com o método, seja possível estabelecer valores de corte sempre proporcionais aos dados da cidade em análise.

Desta forma, propõe-se que o valor de corte seja um percentual estabelecido com base nos dados referentes às atividades de comércio e prestação de serviços do centro principal. Para tal, considerase dois valores, a saber: i) valor de densidade de empresas de comércio e serviços do centro principal; e ii) quantidade de empresas de comércio e serviços do centro principal. Este percentual pode ser estabelecido a partir do cálculo de decis.

Os decis são valores que dividem os dados em décimas partes (cada parte tem $10 \%$ dos dados), sendo indicados por $D_{1}, D_{2}, D_{3}, D_{4}, D_{5}, D_{6}, D_{7}, D_{8}$ e $D_{9}$. Nos decis, a série é dividida em dez partes iguais com o mesmo número de elementos, de tal forma que cada intervalo do decil contém $10 \%$ dos elementos coletados (SILVA, 2011).

- o primeiro decil $\left(D_{1}\right)$ separa os primeiros $10 \%$ dos elementos da série;

- o segundo decil $\left(D_{2}\right)$ separa os primeiros $20 \%(10 \%+10 \%)$ dos elementos da série;

- o terceiro decil $\left(D_{3}\right)$ separa os primeiros $30 \%(10 \%+10 \%+10 \%)$ dos elementos da série.

E assim sucessivamente até o decil $D_{9}$.

- O nono decil ( $\left.D_{9}\right)$ separa os primeiros $90 \%$ dos elementos da série.

Os decis $D_{1}, D_{2}, D_{3} \ldots D_{9}$ podem ser generalizados pela notação $D_{k}$, sendo que o decil considerado é representado por $k$, conforme a equação 1 :

$$
D_{k}=\frac{K \cdot N}{10}
$$

Onde:

$K=$ número do decil considerado;

$N=$ valor

Para o valor de corte de densidade de empresas de comércio e serviços,

$K=$ Decil;

$N=$ Valor de densidade do centro principal.

Para o valor de corte do quantitativo de empresas de comércio e serviços,

$K=$ Decil;

$N=$ Somatório de empresas de comércio e serviços localizadas no centro principal.

\section{Dos cálculos de densidade}

\section{Do centro principal}

Para obter o valor de densidade de empresas comércio e serviços do centro principal, considera-se o total de empresas de comércio e serviços localizadas no mesmo e sua área em $\mathrm{km}^{2}$, conforme equação 2.

$$
D=\frac{\Sigma}{A}
$$

Onde:

$D=$ Densidade de empresas comércio e serviços;

$\Sigma$ = Somatório do número de empresas de comércio e serviços localizadas no centro principal;

$A=$ Área em $\mathrm{km}^{2}$ do centro principal.

$\begin{array}{lllll}\text { Caminhos de Geografia } & \text { Uberlândia-MG } & \text { v. 23, n. } 85 & \text { fev./2022 } & \text { p. 293-314 Página } 303\end{array}$




\section{Dos bairros em análise}

Para obter o valor de densidade de empresas de comércio e serviços de um bairro, considera-se o total de empresas localizadas no mesmo e sua área em $\mathrm{km}^{2}$, conforme equação 3.

$$
D=\frac{\Sigma}{A}
$$

Onde:

$D$ = Densidade de empresas de comércio e serviços;

$E$ = Somatório do número de empresas de comércio e serviços localizadas no bairro;

$A=$ Área $^{1}$ do bairro em $\mathrm{km}^{2}$

Os dados de área em $\mathrm{km}^{2}$ podem ser obtidos em órgãos públicos. Em caso de não disponibilidade, o pesquisador pode utilizar a ferramenta para medida de áreas em $\mathrm{km}^{2}$ disponível no Google Earth ou Google Maps. Cabe destacar que para medição da área do bairro $\mathrm{em} \mathrm{km}^{2}$, deve-se desconsiderar áreas verdes ou de preservação ambiental, a fim de possibilitar uma análise equivalente, considerando uma ocupação homogênea dos bairros em análise. O pesquisador deve se atentar ainda para a presença de áreas pouco ocupadas, a exemplo de loteamentos ociosos, pois essa característica pode interferir no valor de densidade.

\section{Da classificação dos subcentros identificados}

Propõe-se que a classificação dos subcentros seja feita considerando a quantidade de empresas de comércio e serviços. De acordo com Corrêa (1989), Villaça (2001) e Silva (2001), o subcentro se caracteriza por sua significativa concentração comercial. Sendo assim, considerar a quantidade de empresas possibilita corresponder aos conceitos teóricos. Destarte, a posição classificatória é definida pela quantidade de empresas de comércio e serviços existentes no subcentro.

\section{Da base de dados}

Para aplicação do procedimento em cidades brasileiras, os dados podem ser obtidos através do Cadastro Nacional da Pessoa Jurídica (CNPJ). Os dados são fornecidos pela Receita Federal. As informações que estão disponíveis ao público podem ser acessadas pelo site do órgão. Os dados estão compactados em mega arquivos, cabe ao pesquisador filtrar os dados referentes à cidade em estudo. A partir do número do CNPJ, é possível obter dados sobre: nome da empresa; porte; endereço, contendo estado de localização, município, bairro e logradouro; CEP; meios para contato; data de abertura; situação; capital social; segmento; e outras informações.

\section{APLICAÇÃO DO PROCEDIMENTO METODOLÓGICO}

Como descrito anteriormente, o procedimento metodológico proposto consiste em identificar subcentros a partir de valores de corte. São considerados subcentros bairros com densidade e quantidade de empresas de comércio e serviços maior ou igual aos valores de corte estabelecidos.

O procedimento desenvolvido é aplicado ao caso de estudo de um município brasileiro, Anápolis, no estado de Goiás. Este tópico busca mostrar a aplicação do procedimento metodológico, assim como sua validade, a partir de sua aplicação na referida cidade. A aplicação se dá em três fases. Primeiramente, apresenta-se a primeira Fase, de tratamento dos dados. Posteriormente, apresenta-se a Fase 2, de estabelecimento dos valores de corte. Por fim, na terceira fase, apresenta-se os resultados da aplicação do procedimento e análise dos subcentros identificados. A análise é realizada à luz do referencial teórico apresentado na sessão "Identificação de Subcentros Urbanos".

\section{Contextualização da área objeto de estudo}

Para teste e validação, o procedimento metodológico proposto é aplicado na cidade de Anápolis, estado de Goiás, Brasil. O município tem população de 391.772 habitantes (estimativa para 2020, segundo o IBGE), sendo o maior do interior de Goiás e o sexto maior do centro-oeste brasileiro (IBGE, 2019).

Com Produto Interno Bruto - PIB estimado em $\mathrm{R} \$ 14.204 .319,16$ bilhões (IBGE, 2018), o município conta com o segundo maior PIB do estado e o quinto maior do Centro-Oeste brasileiro. O município

${ }^{1}$ Áreas estabelecidas conforme Lei Complementar 218, de 2009 (Anápolis, 2009)

$\begin{array}{llllll}\text { Caminhos de Geografia } & \text { Uberlândia-MG } & \text { v. 23, n. 85 } & \text { fev./2022 } & \text { p. 293-314 } & \text { Página } 304\end{array}$


ocupa, ainda, a primeira posição no ranking de competitividade e desenvolvimento dentre as cidades goianas, segundo a Prefeitura de Anápolis (2013). O município se destaca na produção industrial, tendo o segundo maior polo farmo-químico do Brasil. Sua economia está voltada, sobretudo, para a indústria de transformação, medicamentos e automobilística, localizadas no Distrito Agroindustrial de Anápolis DAIA (PREFEITURA DE ANÁPOLIS, 2013). Quanto ao setor terciário, Anápolis está posicionada na segunda colocação no ranking estadual, com 6,3\% de participação (IMB, 2014). Seu comércio e serviços atraem consumidores provenientes de 34 municípios, incluindo o estado de Goiás e sul do estado de Tocantins (SPOSITO; SPÓSITO, 2006).

\section{Fase 1 - Tabulação dos dados}

Com os dados do Cadastro Nacional da Pessoa Jurídica, o primeiro passo foi filtrar as empresas cadastradas na cidade em estudo, no caso de Anápolis. Foram contabilizadas 39.272 mil empresas. Em seguida, foi necessário filtrar as empresas do segmento comércio e serviços por bairro. No levantamento, foram contabilizadas 34.684 mil empresas do segmento comércio e serviços, distribuídas em 225 bairros de Anápolis. Cabe ressaltar que os dados não são ordenados, cabe ao pesquisador organizar os dados seguindo todas as etapas. Com o número de empresas de comércio e serviços por bairro, o passo seguinte é calcular a densidade empresas de comércio e serviços de todos os bairros da cidade em estudo, conforme critérios elencados na sessão de apresentação do procedimento.

Com os dados do número de empresas por bairro e de densidade de empresas de comércio e serviços por bairro, o passo seguinte é o estabelecimento dos valores de corte, conforme critérios elencados na sessão de apresentação do procedimento.

\section{Fase 2 - Estabelecimento dos valores de corte}

Considerando os critérios elencados na sessão anterior, considera-se que o valor de corte para qualificar um bairro como subcentro equivale ao terceiro decil $\left(\mathrm{D}_{3}\right)$ ou $(10 \%+10 \%+10 \%)$ (conforme justificado na sessão seguinte). Destarte, para se qualificar como subcentro, o bairro em análise deve conter $D_{3}$ da densidade de empresas de comércio e serviços do centro principal e $D_{3}$ do total de empresas do centro principal (conforme critérios salientados na sessão de apresentação do procedimento metodológico). Os critérios estabelecidos possibilitam rigor para definição dos valores de corte, evitando assim estabelecer valores arbitrários, como reputam Baumont; Bourdon (2002). Os valores de corte para Anápolis ficaram em 634 empresas por km²; e 1530 empresas por bairro.

\section{Da escolha do terceiro decil $\left(D_{3}\right)$}

Propõe-se que o valor de corte seja o terceiro decil $\left(D_{3}\right)$. A partir de testes, observa-se que utilizando o primeiro decil $\left(D_{1}\right)$ e o segundo decil $\left(D_{2}\right)$, tem-se valores de corte para densidade de empresas de comércio e serviços ínfimos, visto que os valores ficam próximos da densidade média de empresas de comércio e serviços da cidade. Deste modo, o primeiro decil ( $\left.D_{1}\right)$ e o segundo decil $\left(D_{2}\right)$ não possibilitam que o bairro em análise se sobressaia frente a outros bairros quanto à densidade de comércio e serviços. O valor de corte, situado no $\left(D_{1}\right)$ ou $\left(D_{2}\right)$, também não possibilita que a concentração de empresas de comércio e serviços do bairro em análise seja comparável ao centro principal, visto que o valor mais se compara à média de densidade da cidade do que ao valor de densidade do centro principal, não correspondendo assim aos conceitos teóricos.

Por outro lado, utilizando-se o quarto decil $\left(\mathrm{D}_{4}\right)$, o valor de corte se torna exorbitante para o quantitativo mínimo de empresas, tornando a identificação demasiado rigorosa. Um subcentro, apesar de ser comparável ao centro principal, não chega a deste se aproximar quanto à quantidade de empresas de comércio e prestação de serviços, como salientado e discutido no item 2.

Utilizando-se o terceiro decil $\left(\mathrm{D}_{3}\right)$, tanto para o valor de corte de densidade de comércio e serviços, quanto para o valor de corte do quantitativo mínimo de empresas, tem-se valores adequados para a análise estatística. Utilizando o terceiro decil $\left(D_{3}\right)$, para se qualificar como subcentro, o bairro necessita ter pelo menos o equivalente a $30 \%$ do valor de densidade de empresas de comércio e serviços do centro principal e o equivalente a $30 \%$ da quantidade total de empresas de comércio e serviços do centro principal. O bairro precisa, necessariamente, alcançar os dois valores de corte.

Desta forma, a escolha do terceiro decil $\left(D_{3}\right)$ se dá pela possibilidade de estabelecer valores de corte adequados tanto para densidade de empresas de comércio e serviços quanto para quantidade de empresas de comércio e serviços.

\section{Fase 3 - Análise dos resultados}

Dois bairros da cidade de Anápolis atingiram os valores de corte estabelecidos, a saber, em ordem classificatória: Bairro Jundiaí e Bairro Vila Jaiara (Tabela 1; Figura 1; Tabela 2).
Caminhos de Geografia
Uberlândia-MG
v. 23, n. 85
fev./2022
p. 293-314
Página 305 
Tabela 1 - Subcentros identificados em Anápolis (GO).

\begin{tabular}{lccccc}
\hline $\begin{array}{l}\text { Unidade de } \\
\text { análise }\end{array}$ & $\begin{array}{c}\text { Empresas de } \mathbf{C S}^{2} \\
\left(\mathbf{n}^{\circ}\right)\end{array}$ & Área $\left.\mathbf{( k m}^{2}\right)$ & $\begin{array}{c}\text { Densidade } \\
\text { empresas CS }\end{array}$ & $\begin{array}{c}\text { Valor de corte - } \\
\text { Densidade de } \\
\text { empresas de CS }\end{array}$ & $\begin{array}{c}\text { Valor de corte } \\
\text { Quantidade de } \\
\text { empresas de CS }\end{array}$ \\
\hline Anápolis & 34.684 & - & - & - & - \\
\hline Centro & 5.101 & 2,55 & 2000 & - & 1.530 \\
\hline $\begin{array}{l}\text { Bairro } \\
\text { Jundiaí }\end{array}$ & 2.638 & 2,33 & 1132 & 600 & 1.530 \\
\hline $\begin{array}{l}\text { Bairro Vila } \\
\text { Jaiara }\end{array}$ & 1.818 & 2,54 & 715 & 600 & \\
\hline
\end{tabular}

Fonte - Própria.

Figura 1 - Anápolis (GO): Subcentros identificados, 2020.

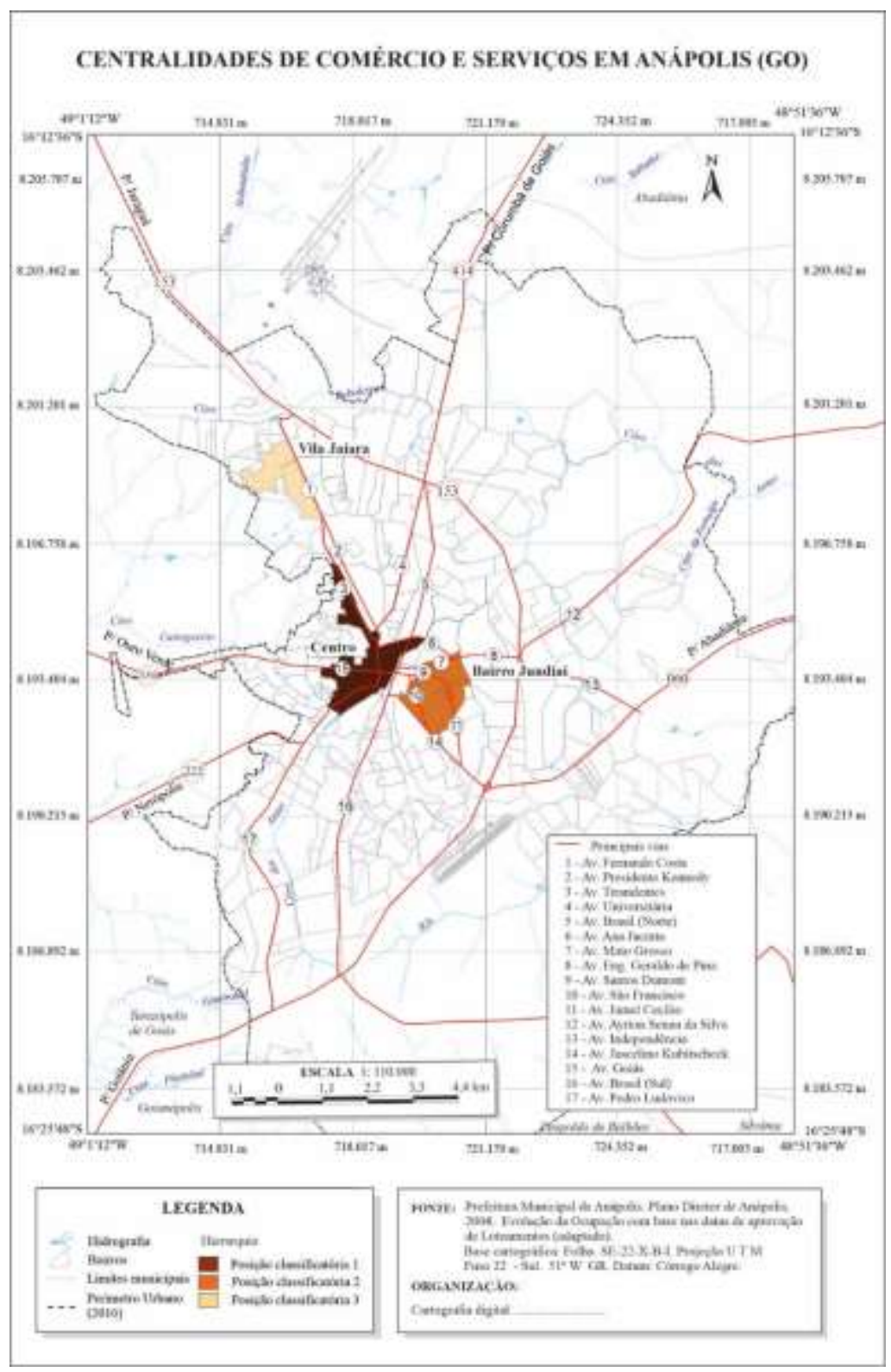

Fonte - Anápolis, 2006. Org: Própria.

2 Empresas de comércio e prestação de serviços

$\begin{array}{lllll}\text { Caminhos de Geografia } & \text { Uberlândia-MG } & \text { v. 23, n. } 85 & \text { fev./2022 } & \text { p. 293-314 Página } 306\end{array}$


Tabela 2 - Classificação dos subcentros identificados em Anápolis, Goiás

\begin{tabular}{lcccc}
\hline Unidade de análise & $\begin{array}{c}\text { Percentual em } \\
\text { relação ao total de } \\
\text { empresas de CS da } \\
\text { cidade }\end{array}$ & $\begin{array}{c}\text { Posição } \\
\text { classificatória por } \\
\text { Quantidade de } \\
\text { empresas de CS }\end{array}$ & $\begin{array}{c}\text { Posição } \\
\text { classificatória por } \\
\text { quantidade de } \\
\text { empresas }\end{array}$ & $\begin{array}{c}\text { Posição } \\
\text { classificatória final }\end{array}$ \\
\hline Centro & $14,7 \%$ & 1 & 1 & 1 \\
\hline Bairro Jundiaí & $7,6 \%$ & 2 & 2 & 2 \\
\hline Bairro Vila Jaiara & $5,2 \%$ & 3 & 3 & 3 \\
\hline
\end{tabular}

Fonte - Própria.

Nota-se que os resultados obtidos com a aplicação do procedimento metodológico desenvolvido neste trabalho se assemelham aos resultados obtidos por outros estudos que objetivaram identificar centralidades em Anápolis. Contudo, são estudos que identificaram centralidades a partir de metodologias qualitativas, dentre estes, destaca-se: Luz (2013), que identificou como subcentros o bairro Jundiaí e o bairro Vila Jaiara; O estudo de Mendonça (2016), que identificou centralidades em escala de setor censitário nos bairros Jundiaí e Vila Jaiara, além de eixos comerciais; e o estudo de Garcia (2012), que identificou como subcentros, os bairros Jundiaí e Vila Jaiara. Já o procedimento proposto neste trabalho é pioneiro quanto à identificação de subcentros de comércio e serviços a partir de metodologia quantitativa. Com a aplicação do procedimento proposto foram identificados dois subcentros: bairro Jundiaí e bairro Vila Jaiara.

\section{Caracterização das centralidades identificadas}

Busca-se, neste tópico, analisar a estrutura urbana policêntrica da cidade estudo de caso - Anápolis a partir da abordagem de Villaça (2001), salientada na primeira sessão deste trabalho. Segundo Villaça (2001), as centralidades podem ser classificadas em: centro tradicional; centro expandido; outros subcentros; e shoppings centers.

Com a aplicação do procedimento metodológico proposto, foram identificados dois subcentros de comércio e serviços na cidade de Anápolis. Em ordem classificatória, conforme critérios de classificação elencados na sessão de apresentação do procedimento, são: Bairro Jundiaí; e Bairro Vila Jaiara. Na sequência, são apresentados e caracterizados esses subcentros, em conjunto com o centro tradicional.

\section{Centro tradicional (Setor Central)}

Segundo Maia; Whitacker; Silva (2017), muitas das cidades médias brasileiras que se constituíram no período ferroviário tiveram seu centro erigido e consolidado em função deste período. Nessas cidades, o núcleo central foi fortalecido pelas relações comerciais ligadas ao uso da estação ferroviária e as oportunidades de acesso o demarcaram como uma centralidade expressa e consolidada.

No caso da cidade de Anápolis, os trilhos assumiram um importante papel em seu contexto socioeconômico. O município experimentou um notável desenvolvimento econômico e populacional para a época, evidenciando o sucesso da ferrovia: "o desenvolvimento econômico de forma notória deu-se a partir da chegada da ferrovia, pois os trechos rodoviários existentes eram precários, possuindo uma péssima conservação. Com a chegada da ferrovia o comércio passou a se desenvolver em níveis superiores ao setor primário [...]" (OLIVEIRA, 2016, p. 363).

A ferrovia permaneceu no núcleo central da cidade até a década de 1970. Sua estação ainda hoje permanece (como patrimônio histórico) localizada no centro tradicional. Com a expansão do núcleo central, os trilhos passaram a gerar transtornos, tornando-se um obstáculo à ampliação da área urbana, o que levou à sua retirada no ano de 1976. O prédio da estação se tornou ponto provisório para atividades públicas até se tornar parte integrante do terminal urbano da cidade (OLIVEIRA, 2016). A leitura de Maia; Whitacker; Silva (2017) quanto à influência do período ferroviário na estrutura urbana das cidades médias e, mais especificamente, a formação do centro tradicional, é válida para a cidade de Anápolis. De fato, o centro tradicional da cidade se encontra localizado na porção mais antiga do núcleo urbano, onde se localizava a estação ferroviária. Muitas das cidades médias tiveram seu centro fortalecido por conta deste período, isto é, por conta das relações comerciais sediadas no mesmo.

$\begin{array}{lllll}\text { Caminhos de Geografia } & \text { Uberlândia-MG } & \text { v. 23, n. } 85 & \text { fev./2022 } & \text { p. 293-314 Página } 307\end{array}$


O centro tradicional de Anápolis (oficialmente denominado de Setor Central) é o maior bairro em população (Prefeitura de Anápolis, 2010) e a maior centralidade da cidade, com 5101 empresas de comércio e prestação de serviços e densidade de 2000 empresas de comércio e serviços por km².

A partir da manipulação do banco de dados desenvolvido para este trabalho, nota-se que o centro tradicional da cidade abriga grandes empreendimentos. Dentre estes, o maior shopping center da cidade, inaugurado em 2009, e o maior centro comercial ${ }^{3}$, inaugurado recentemente, em 2019. Este último abriga o primeiro heliponto do município. Além desses, está em fase de construção um complexo mixed-use, com hospital privado, salas comerciais, shopping center e residencial (condomínio vertical). Ademais, o maior camelódromo da cidade e outros cinco shoppings centers de pequeno porte (menos de 50 lojas) se localizam no centro tradicional.

Segundo Villaça (2001), há uma tendência para instalação destes empreendimentos em centralidades, o que, consequentemente, eleva seu poder polarizador. Essa tendência pode ser observada no caso de Anápolis. Dois dos três shoppings centers com mais de 50 lojas e todos os cinco com menos de 50 lojas se localizam em centralidades. Além destes, está em fase de construção um shopping center de grande porte em seu centro tradicional.

O mesmo ocorre para as galerias, camelódromos e complexos comerciais. Seis das oito galerias se localizam em centralidades e, ainda, outras 2 estão em fase de construção no subcentro Bairro Jundiaí. Ademais, os dois camelódromos e os dois complexos comerciais existentes na cidade se localizam em centralidades. Além desses, estão em fase de construção, no subcentro Bairro Jundiaí, outros 2 complexos comerciais e outras duas galerias comerciais.

Apesar do surgimento de novas centralidades, observa-se que o centro tradicional de Anápolis continua sendo atrativo para empreendimentos comerciais. Sua acessibilidade o qualifica como uma centralidade potencial.

Conforme abordado na primeira sessão deste trabalho, o centro o é por sua acessibilidade, de maneira que sem esse atributo, dificilmente o mesmo atrairia para si empreendimentos comerciais (VILLAÇA, 2001). Tal como ocorre com os subcentros, a consolidação da centralidade do centro tradicional envolve vários fatores, dentre os quais destaca-se o papel da acessibilidade. A facilidade de acesso à uma determina área, concretizada por meio de infraestruturas viárias, de transportes, dentre outras, gera intensa circulação. Para o mercado, estar próximo a áreas com intensa circulação é estratégico para um empreendimento, considerando o mercado consumidor em potencial (SILVA, 2001).

No caso específico do centro de Anápolis, a acessibilidade ao mesmo, concretizada pelo sistema viário e pelo transporte, o potencializa como uma centralidade de comércio e serviços. O setor conta com vias arteriais que permitem interligar o mesmo a todas as regiões intra-urbanas da cidade. Conforme pode ser observado na Figura 1, as vias que ligam o centro tradicional às regiões intra-urbanas da cidade são: Avenida Brasil, com 14 km de extensão, permitindo acesso às regiões Norte, Nordeste, Sul e Sudeste; Avenidas Presidente Kennedy/Fernando Costa, com $6 \mathrm{~km}$ de extensão, permitindo acesso à região Noroeste; Avenida Pedro Ludovico, com 9,2 km de extensão, permitindo acesso à região Sudoeste; Avenida Goiás com, 3,1 km de extensão, permitindo acesso à região Oeste; Avenidas Mato Grosso/Geraldo de Pina, com 2,6 km de extensão, permitindo acesso à região Leste; e Avenida Jk, com 3,0 km de extensão, permitindo acesso à região Leste. O único setor acessível a qualquer região intraurbana por meio de vias arteriais é o centro tradicional.

Ainda no que tange à acessibilidade, cabe destacar o papel do transporte público coletivo. O centro abriga a única Estação Central (terminal de ônibus) da cidade. O sistema de transporte público é integrado. Todas as 97 linhas ofertadas partem da Estação Central, interligando de forma direta todos os bairros e distritos. Diariamente, cerca de 1039 viagens são realizadas a partir da Estação Central (URBAN, 2020). Esse sistema amplia o movimento de pessoas no centro tradicional de forma considerável.

Observa -se que a Estação Central se qualifica, considerando a abordagem de Kneib (2008), como um Polo Gerador de Viagens. Conforme salientado na primeira sessão deste trabalho, os PGV geram intensa circulação de pessoas, por este motivo, tornam-se locais atrativos para atividades comerciais.

${ }^{3}$ Centro comercial é "uma estrutura que contém estabelecimentos comerciais [...]. É um espaço planejado sob uma administração centralizada, composto de lojas destinadas à exploração comercial e à prestação de serviços, sujeitas a normas contratuais padronizadas" (JusBrasil, [s. d.]). 
Outro fator a se considerar, é que o único corredor exclusivo para transporte público coletivo (com extensão de aproximadamente $14 \mathrm{~km}$ ), que liga a região Sul da cidade à região Norte, passa pelo centro.

Factualmente, a acessibilidade do centro tradicional de Anápolis o confere atributos para que o mesmo seja considerado um setor atrativo para empreendimentos comerciais.

\section{Bairro Jundiaí - Centro expandido}

À luz da abordagem de Villaça (2001), conforme discutido na primeira sessão deste trabalho, o bairro Jundiaí se qualifica como centro expandido. O centro expandido é o centro formado pelas e para as camadas de alta renda. Este centro surge na esteira da deterioração do centro tradicional, processo que, no contexto das cidades brasileiras, teve início em meados das décadas de 1960/70.

No caso do centro expandido de Anápolis - Bairro Jundiaí - observa-se que, desde sua fundação (ao fim da década de 1940), o bairro apresentou características do que viria a ser o centro expandido. Conforme pode ser observado na Figura 2, o Boletim Publicitário do bairro Jundiaí, publicado pela Sociedade Imobiliária de Anápolis, no ano de 1949, o denominou como: "nova Anápolis", "o futuro", e "lugar saudável". Por outro lado, o centro tradicional foi chamado de "parte antiga da cidade". A partir desse registro, é possível observar que, no caso de Anápolis, o processo de desvalorização do centro tradicional, em detrimento da valorização do primeiro bairro nobre a surgir na cidade, iniciou-se antes mesmo das décadas de 1960/70.

Figura 2 - Anápolis (GO) Boletim Publicitário Bairro Jundiaí- Sociedade Imobiliária de Anápolis, 1949.

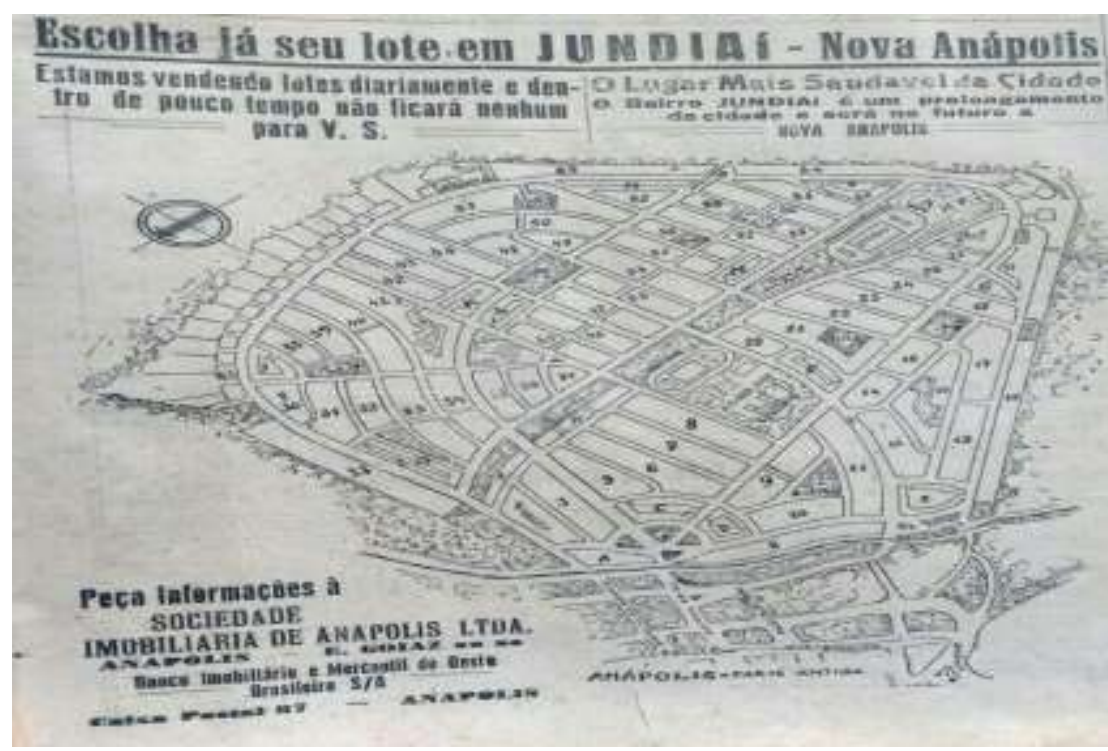

Fonte - Acervo Museu Histórico Alderico Borges de Carvalho, 2018.

Desde então, o bairro cresceu e se valorizou, se tornando o mais nobre bairro da cidade. Na Planta Genérica de Valores da prefeitura de Anápolis (Anápolis, 2009), o Jundiaí possui o valor por metro quadrado mais caro da cidade, com preço médio de $\mathrm{R} \$ 135,49$ por $\mathrm{m}^{2}$. À efeito de comparação, o preço do metro quadrado no subcentro Bairro Vila Jaiara custa em média $R \$ 38,32$ (ANÁPOLIS, 2009).

O Jundiaí é o segundo maior bairro em população (Prefeitura de Anápolis, 2010) e o maior subcentro de comércio e serviços da cidade, com 2638 empresas de comércio e serviços e densidade de 1132 empresas de comércio e serviços por $\mathrm{km}^{2}$. À efeito de comparação, o subcentro Bairro Vila Jaiara concentra 1818 empresas de comércio e serviços e densidade em 693 empresas por km². O bairro Jundiaí abriga filiais de redes de comércio e serviços municipais, estaduais, nacionais e internacionais, sendo, em sua maioria, voltadas para consumo de alto padrão.

A partir do banco de dados desenvolvido neste trabalho, observa-se que o Jundiaí abriga estabelecimentos de comércio e serviços e equipamentos urbanos de destaque, tais como: o maior

$\begin{array}{lllll}\text { Caminhos de Geografia } & \text { Uberlândia-MG } & \text { v. 23, n. } 85 & \text { fev./2022 } & \text { p. 293-314 Página } 309\end{array}$


teatro da cidade; a maior escola particular; um dos dois campus da Universidade Estadual de Goiás; a Faculdade SENAI; o SESC da cidade; um dos dois SESI; o Hospital Santa Casa do munícipio; e sedes de instituições governamentais. O bairro não possui shopping center, mas abriga 4 galerias comerciais, tendo outras 2 em fase de construção. O bairro possui, ainda, 2 complexos comerciais de grande porte em fase de construção.

A alta concentração comercial e de equipamentos urbanos do bairro pode ser explicada por sua desenvolvida acessibilidade. Conforme pode ser observado na Figura 1, o bairro possui diversas vias de acesso. Cabe destacar que as Avenidas Mato Grosso e JK são as únicas vias que possibilitam acesso entre a região Leste e o centro tradicional. Ademais, passa pelo bairro, a maior avenida da cidade, a Avenida Brasil. Conforme discutido na primeira sessão deste trabalho, áreas com desenvolvida acessibilidade geram intensa circulação de veículos e pessoas, por este motivo, são locais estratégicos para localização de estabelecimentos comerciais.

\section{Bairro Vila Jaiara - Subcentro popular}

O bairro Vila Jaiara foi fundado na década de 1940 pelo engenheiro Luiz Caiado de Godoy, cuja área pertencia às fazendas Gomes e Reboleira. Contudo, o bairro só veio a progredir após a instalação da Companhia Goiana de Fiação e Tecelagem de Algodão, antiga Vicunha S/A-Indústrias Reunidas (GARCIA, 2012). Desde então, o bairro cresceu e se tornou o terceiro maior bairro em população, atrás apenas do Setor Central e do bairro Jundiaí (PREFEITURA DE ANÁPOLIS, 2010).

À luz da abordagem de Villaça (2001), conforme discutido na primeira sessão deste trabalho, o bairro Vila Jaiara se qualifica como um subcentro popular. O subcentro popular se caracteriza pela concentração de comércio e serviços voltados para o consumo de classes com poder aquisitivo médio.

O bairro Vila Jaiara é o segundo maior subcentro da cidade, com 1818 empresas de comércio e serviços e densidade de 715 empresas de comércio e serviços por $\mathrm{km}^{2}$. O bairro possui estabelecimentos de comércio e serviços diversificados, com empresas independentes e filiais de redes municipais, estaduais, nacionais e internacionais. A partir do banco de dados, observa-se que o bairro abriga estabelecimentos de comércio e serviços e equipamentos urbanos de destaque, tais como: um shopping center de grande porte; um dos dois camelódromos existentes na cidade; uma faculdade; um dos dois SESI da cidade e instituições governamentais.

Como destacado, o bairro é um subcentro popular, não há concentração elevada de estabelecimentos de comércio e serviços de alto padrão, tal como possui o subcentro bairro Jundiaí. Na Planta Genérica de Valores da prefeitura de Anápolis (Anápolis, 2009), o bairro Vila Jaiara possui preço médio de $R \$$ 38,32 \$ por $\mathrm{m}^{2}$, valor bem inferior ao do subcentro bairro Jundiaí, $R \$ 135,49$ por $\mathrm{m}^{2}$ (ANÁPOLIS, 2009).

A alta concentração de comércio, serviços e equipamentos urbanos do bairro pode ser explicada por sua acessibilidade. O bairro não é dotado de grandes vias tal como o subcentro bairro Jundiaí, contudo, possui a terceira maior avenida em extensão do munícipio, a Avenida Fernando Costa, que permite acesso direto ao centro da cidade. Por sua acessibilidade, a Avenida Fernando Costa é o principal ponto comercial do Bairro, onde, inclusive, se localiza o shopping center, o camelódromo, a faculdade, e outros dos principais estabelecimentos de comércio e serviços e equipamentos urbanos do bairro.

\section{CONSIDERAÇÕES FINAIS}

O presente trabalho objetivou desenvolver um procedimento metodológico para identificação de subcentros a partir da variável comércio e serviços. $O$ trabalho desenvolveu um procedimento metodológico quantitativo baseado em valores de corte. Destarte, foram considerados como subcentros, bairros com densidade de comércio e serviços e total de empresas de comércio e serviços acima dos valores de corte estabelecidos. O estudo criou um procedimento específico para o estabelecimento dos valores de corte, a fim de estabelecer valores adequados.

Para teste e validação, o procedimento foi aplicado na cidade de Anápolis. A aplicação piloto demonstrou a eficácia do procedimento para o objetivo proposto. Como resultados, foram identificados 2 subcentros na referida cidade. Os subcentros identificados foram analisados à luz do referencial teórico do trabalho e a análise demonstrou que o subcentro bairro Jundiaí se caracteriza como centro expandido e o subcentro bairro Vila Jaiara como subcentro popular.

$\begin{array}{llllll}\text { Caminhos de Geografia } & \text { Uberlândia-MG } & \text { v. 23, n. } 85 & \text { fev./2022 } & \text { p. 293-314 } & \text { Página } 310\end{array}$


O trabalho procurou desenvolver um procedimento que possibilite localizar, caracterizar e identificar subcentros de comércio e serviços, buscando uma contribuição teórica e aplicada sobre o estudo das centralidades urbanas de comércio e serviços. Portanto, espera-se que o procedimento desenvolvido possa contribuir com outros estudos que objetivem identificar e analisar subcentros, processo este tão importante para planejamento urbano, nas diversas ciências e disciplinas que dele participam.

\section{AGRADECIMENTOS}

O presente trabalho foi realizado com apoio da Coordenação de Aperfeiçoamento de Pessoal de Nível Superior Brasil (CAPES) - Código de Financiamento 001.

\section{REFERÊNCIAS}

ÁLVAREZ, D. A. O urbano: um espaço ocupado pelo automóvel. In: RIBEIRO F. V. Dinâmica urbana: comércio, serviços e fluxos. Uberlândia: Edibrás, 2015.

ANÁPOLIS. Lei complementar $n^{\circ}$ 128, de 10 de outubro de 2006. Dispõe sobre o Plano Diretor participativo do município de Anápolis. Revoga as Leis ordinárias $n^{\circ}$ 2.077/1992, no 2.079/1992 e as leis complementares $n^{\circ}$ 025/2002, nº 058/2003 e dá outras providências. Anápolis, 2006. Disponível em:

<https://www.google.com/url?sa=t\&source=web\&rct=j\&url=https://www.sistemafieg.org.br/repositoriosi tes/repositorio/portalfieg//editor//mage///condur/PLANO_DIRETOR_ANAPOLIS.pdf\&ved=2ahUKEwiF wqSWoL_uAhW9HbkGHRfLADkQFjABegQIAhAB\&usg=AOvVaw2gi-

EoYDMpm_FyD3kW8sB6> Acesso em 28 de janeiro de 2021.

. Lei complementar $n^{\circ} 221$, de 30 de dezembro de 2009. Dispõe sobre alteração na lei complementar $n^{\circ} 136$, de 28 de dezembro de 2006 - Código tributário e de rendas do município de Anápolis e dá outras providências. Anápolis, 2009. Disponível em:

$<$ https://leismunicipais.com.br/a/go/a/anapolis/lei-complementar/2009/23/221/lei-complementar-n-2212009-dispoe-sobre-alteracao-na-lei-complementar-n-136-de-28-de-dezembro-de-2006-codigotributario-e-de-rendas-do-municipio-de-anapolis-e-da-outras-providencias $>$ Acesso em 28 de janeiro de 2021.

ANSENSIO, J. Cambios en la forma urbana y demand de transporte. PhD thesis, Universitat Autònoma de Barcelona, 2000.

ATM. Autoritat del Transport Metropolitá. Diagnosi del sistema i directrius del pla director d'infraestructures. Barcelona, 1998.

BALSAS, C. J. Urbanismo comercial em Portugal e a revitalização do centro das cidades. Lisboa: Gabinete de estudos e prospectiva econômica (Ministério da Economia), 1999.

BAUMONT, C; BOURDON F. Centres secondaires et recomposition économique des espaces urbain, le casda communauté de l'aglomération dijonnaise (1990; 1999). LATEC Working Paper 4, Universidade de Bourgogne, Dijon, 2002.

CORRÊA, R. L. O espaço urbano. São Paulo: editora Ática, 1989.

DE SOUZA NETO, S.; BENIGNO, J.; SILVEIRA, J.; RIBEIRO, E. L. Acessibilidade, mobilidade e formas de promover a reabilitação do espaço urbano: o caso da cidade de João Pessoa-PB. João Pessoa: Cadernos de pós-graduação em Arquitetura e Urbanismo, v. 13, n. 12, p. 26-26. 2013.

DEVAI, L. E. A formação de novas centralidades a partir de shoppong-centers em Londrina.

Geografia e Pesquisa, v. 8, n. 1. 2014. Disponível em: vampira.ourinhos.unesp.br/openjournalsystem/index.php/geografiaepesquisa/article/view/179 Acesso em: 27 de outubro de 2020.

DUARTE, H. S. A cidade do Rio de Janeiro: descentralização das atividades terciárias. Os centros funcionais. Revista Brasileira de Geografia, v. 35, n. 1, p. 53-98. 1974.

GARCIA, V. T. Dinâmicas urbanas recentes: o setor terciário, descentralização e a formação de novos pontos de comércio em Anápolis (GO). Dissertação (Mestrado em Geografia). Brasília: UNB, 2012.

$\begin{array}{lllll}\text { Caminhos de Geografia } & \text { Uberlândia-MG } & \text { v. 23, n. } 85 & \text { fev./2022 } & \text { p. 293-314 Página } 311\end{array}$


GIULIANO, G.; SMALL, K. A. Subcenters in the los angeles region. Regional Science and Urban Economics , 163-182, 1991. Disponível em: https://escholarship.org/uc/item/6ts0t95w Acesso em: 27 de outubro de 2020. https://doi.org/10.1016/0166-0462(91)90032-I

IBGE. Instituto Brasileiro de Geografia e Estatística. Regiões de Influência das Cidades 2007 (2008). Rio de Janeiro, 2008. Disponível em:

$<$ https://www.google.com/url?sa=t\&source=web\&rct=i\&url=https://biblioteca.ibge.gov.br/visualizacao/li vros/liv40677.pdf\&ved=2ahUKEwjTgo vtL uAhWMLLkGHRXnAtQQFiABegQIAhAB\&usg=AOvVaw2J 1XFtmLkngOVeOyrQji1l> Acesso em 28 de janeiro de 2021.

Instituto Brasileiro de Geografia e Estatística. Produto interno bruto dos municípios brasileiros. Rio de Janeiro, 2018. Disponível em:

<https://sidra.ibge.gov.br/tabela/5938\#/n6/5201108/v/37/p/last\%201/d/v37\%200///v,p,t/resultado> Acesso em 28 de janeiro de 2021.

Instituto Brasileiro de Geografia e Estatística. Estimativas da população residente no

Brasil e unidades da federação com data referência em 10 de julho de 2020. Instituto Brasileiro de Geografia e Estatística. Rio de Janeiro, 2019. Disponível em:

$<$ https://www.ibge.gov.br/estatisticas/sociais/populacao/9103-estimativas-de-

populacao.html?edicao=28674\&t=resultados $>$ Acesso em 28 de janeiro de 2021 .

IMB. Instituto Mauro Borges de estatísticas e estudos socioeconômicos. Setor de serviços goiano: uma análise em perspectiva histórica. Goiânia, 2014. Disponivel em:

$<$ https://www.google.com/url?sa=t\&source=web\&rct=i\&url=https://www.imb.go.gov.br/files/docs/public acoes/estudos/2017/setor-servicos-goiano-uma-analise-em-perspectivahistorica.pdf\&ved=2ahUKEwjilKnAmb uAhUBILkGHfNFDUUQFjAAegQIBBAC\&usg=AOvVaw0P. HLAohwOofNZRkDtX6G6> Acesso em 28 de janeiro de 2021.

. Instituto Mauro Borges de estatísticas e estudos socioeconômicos. Síntese de Indicadores Socioeconômicos do Instituto Mauro Borges (IMB). Goiania, 2016.

JUSBRASIL, [s. d.]. Conceito de Centro comercial.

Disponível em: https://www.jusbrasil.com.br/topicos/303965/shopping-center/legislacao Acesso em 2 de fevereiro de 2021.

KNEIB, E. C. Subcentros Urbanos: Contribuição Conceitual e Metodológica à sua definição e identificação para planejamento de Transportes. Tese (Doutorado em transportes). Brasília: UNB, 2008.

LESSA, Daniela A. Mobilidade e acessibilidade ao transporte coletivo por ônibus: evidências e contradições no caso de Belo Horizonte-MG. Tese (Doutorado em Geografia) - Belo Horizonte: UFMG. 2019.

LITMAN, T. Evaluating accessibility for transportation planning. Victoria: Victoria Transport Policy Institute, 2008.

LÓPEZ, Garcia; MUÑIZ Iván. Employment descentralisation: polycentric compaction or sprawl? The case of the Barcelona Metropolitan Region 1986-1996. Barcelona: Universitat Autònoma de Barcelona, 2006.

LUZ, J.. As cidades médias e as novas centralidades: a análise da formação de subcentros e eixoa comerciais em Anápolis (GO). In: Anais do Colóquio Nacional Henri Lefebvre: Produção e Reprodução do Espaço Urbano nas Cidades Brasileiras. 2013, v. 3 n. 1. Disponível em: https://www.anais.ueg.br/index.php/sineep/article/view/6680 Acesso em 27 de outubro de 2020.

MARTORI, J. C.; SURIÑAC, J. Urban population density functions: the case of the Barcelona region. Universitat de Vic. 1-18, 2002. Disponível em: <http://repositori.uvic.cat/handle/10854/405> Acesso em 2 de fevereiro de 2021.

MENDONÇA, F. Reestruturação de redes de transporte coletivo a partir da identificação de centralidade em cidades de médio porte: procedimento metodológico e definição de diretrizes. Dissertação (Mestrado em Projeto e Cidade) - Goiânia: UFG. 2016.

MAIA, S.; WHITACKER, M.; SILVA, R. Centro e centralidade em cidades médias. São Paulo: Cultura Acadêmica, 2017. 1 ed. 
MCDONALD, J. F. The identification of urban employment subcenters. Journal of Urban Economics, v. 21, n. 2, p. 242-258. 1987. Disponível em:

https://www.sciencedirect.com/science/article/abs/pii/0094119087900179 Acesso em: 27 de outubro de 2020. https://doi.org/10.1016/0094-1190(87)90017-9

MCDONALD, J. F.; MCMILLEN, D. P. Employment subcenters and subsequent real estate development in suburban Chicago. Journal of Urban Economics, v. 48, n. 1, p. 135-157, 2000. Disponível em: https://www.sciencedirect.com/science/article/abs/pii/S0094119099921605 Acesso em: 27 de outubro de 2020. https://doi.org/10.1006/juec.1999.2160

MCMILLEN, Daniel P. Nonparametric employment subcenter identification. Journal of Urban economics, v. 50, n. 3, p. 448-473, 2001. Disponível em:

https://www.sciencedirect.com/science/article/abs/pii/S0094119001922284 Acesso em: 27 de outubro de 2020. https://doi.org/10.1006/juec.2001.2228

MUSEU HISTÓRICO ALDERICO BORGES DE CARVALHO. Acervo fotográfico. Anápolis, 2018.

OLIVEIRA, M. F. Nos trilhos da ferrovia: a estação ferroviária de Anápolis (GO) como lugar de memória e poder. Revista Fragmentos de Cultura-Revista Interdisciplinar de Ciências Humanas, v. 26, n. 3, p. 359-370, 2016. Disponível em:

http://revistas.pucgoias.edu.br/index.php/fragmentos/article/view/4626 Acesso em: 27 de outubro de 2020. https://doi.org/10.18224/frag.v26i3.4626

PANERAI, P. Análise Urbana. Brasília: Editora UnB, 2014.

PEREIRA, S. A ação do Estado na reestruturação espacial dos equipamentos urbanos. Formação, v. 1, n. 8, 2001.

PREFEITURA DE ANÁPOLIS. População estimada dos bairros de Anápolis em 2010. Prefeitura Municipal de Anápolis. Anápolis, 2010. Disponível em:

$<$ http://www.anapolis.go.gov.br/bde/BairAnapolis.php $>$ Acesso em 28 de janeiro de 2021

Boletim Informativo de Desenvolvimento Econômico de Anápolis. SEMDEA - Secretaria Municipal de Desenvolvimento Econômico e Agricultura. Anápolis, 2013. Disponível em: $<$ https://www.google.com/url?sa=t\&source=web\&rct=j\&url=http://www.anapolis.go.gov.br/portal/arquiv os/files/Boletim\%2520completo.pdf\&ved=2ahUKEwiLtYOFI7_uAhVnI7kGHYcwDVoQFjABegQIARAB \&usg=AOvVaw0-fSLK193tyTgdc6pnETrB > Acesso em 28 de janeiro de 2021.

RODRIGUES, F. A. da C.; BELMIRO, C. H. P.; SILVEIRA NETO, R da M. Monocentrismo e estrutura urbana: uma análise empírica para a ciade do Recife. 23ํㅡㄹ Encontro Regional de Economia; 24을

Forum Banco do Nordeste de Desenvolvimento. ANPEC/Banco do Nordeste do Brasil, Fortaleza, 2018. Disponível em: https://www.anpec.org.br/encontro/2018/submissao/files l/i100adb8cb6e19a4c9a4945a444d52d1541.pdf Acesso em: 21 de janeiro de 2021.

SILVA, R. W. Novos centros, novas centralidades, novas diferenças A fragmentação do espaço urbano em Londrina. Dissertação (Dissertação em Geografia) - Rio Claro: FCT/UNESP. 2004.

Centro e centralidade: uma discussão conceitual. Formação, v. 1, n. 8, p. 107 - 115. 2001. Disponível em: https://revista.fct.unesp.br/index.php/formacao/article/view/1209 Acesso em: 27 de outubro de 2020.

SPOSITO, E. S.; SPOSITO, M. E; Cidades Médias: produção do espaço urbano e regional. São Paulo: Expressão Popular, 2006.

SPOSITO, M. E. (Org.). A nova vida do velho centro nas cidades portuguesas e brasileiras. Porto: Faculdade de Letras-CEGOT, 2013.

A gestão do território e as diferentes escalas da centralidade urbana. Território, v. 3, n. 4, Ano III, n. 4, p. 27-37. 1998.

. Novas formas comerciais e redefinição da centralidade intra-urbana. In: SPOSITO, Maria Encarnação Beltrão (Org.). Textos e contextos para a leitura geográfica de uma cidade média. Presidente Prudente: FCT/UNESP, 2001.

SMALL, Kenneth A.; SONG, Shunfeng. Population and employment densities: structure and change. Journal of urban economics, v. 36, n. 3, p. 292-313, 1994. Disponível em: 
https://www.sciencedirect.com/science/article/abs/pii/S0094119084710370 Acesso em: 27 de outubro de 2020. https://doi.org/10.1006/juec.1994.1037

SILVA, A. L. Introdução à Análise de Dados. Rio de Janeiro: E-papers, 2011.

SIQUEIRA, L. P. Identificação de subcentros na cidade de São Paulo: uma abordagem ligada à nova economia urbana. Dissertação (Mestrado em economia política). São Paulo: PUC-SP. 2012.

. Proposta metodológica para a identificação de subcentros urbanos: estudo de caso na região metropolitana de São Paulo. Economia Aplicada, v. 18, n. 1, p. 139-165. 2014. Disponível em: https://www.scielo.br/scielo.php?pid=S1413-80502014000100007\&script=sci arttext\&tlng=pt Acesso em: 27 de outubro de 2020. https://doi.org/10.1590/1413-8050/ea476

URBAN. Itinerários transporte coletivo público de Anápolis. Mobilidade Urbana de Anápolis. Anápolis, 2020. Disponível em: <http://www.anapolis.go.gov.br/bde/BairAnapolis.php $>$ Acesso em 28 de janeiro de 2021.

VASCONCELLOS, E. A. Transporte urbano nos países em desenvolvimento: reflexões e propostas. São Paulo: Annablume. 2002.

Transporte urbano, espaço e eqüidade: análise das políticas públicas. São Paulo: Annablume, 2001.

VILLAÇA, F. Espaço intra-urbano no Brasil. São Paulo: Studio Nobel FAPESP, 2001.

Recebido em: 28/10/2020

Aceito para publicação em: 02/04/2021 